\title{
Modeling of Peak value in Cylinder Firing Pressure in Diesel Engines using Artificial Neural Network Methodology
}

\author{
Ozan Doğukan BOZDAĞ ${ }^{1}$ Orkun ÖZENER ${ }^{1}$ \\ ${ }^{1}$ Department of Mechanical Engineering, Internal Combustion Engines Laboratory, Y1ldız Technical \\ University, İstanbul,Turkey
}

\begin{abstract}
From the past to the present, restrictions have been imposed on emissions due to the widespread use of internal combustion engines and the environmental damage caused by emissions. Engine manufacturers perform calibration studies by affecting the fuel-air parameters through the engine control unit to ensure emission limits. The maximum pressure due to the inside of the cylinder is called the maximum pressure inside the cylinder. In order for the engine to work properly, there is a cylindrical pressure resistance due to the material strength. When performing calibration work, the maximum pressure inside the cylinder should be monitored and maintained within the strength limits. In-cylinder pressure sensors are used in the in-cylinder pressure monitoring. Because the pressure sensors are exposed to high pressure (more than 200 bar or more in heavily heated), the values they read can be reduced or distorted. In this study, 6 different the artificial neural network (ANN) model design was created and trained with 2400 test points obtained from engine dynamometers system. Then these networks are tested again with 60 unused test points which are not used during training phases. Then the results are analyzed in terms of peak firing pressure difference. The research results showed that 2 neurons ANN system is best ANN system capable of predicting peak firing pressure within 1.7 bar average difference to measured data.
\end{abstract}

Key Words: Diesel Engines, Artificial Neural Networks, Peak Firing Pressure In Cylinder, Experimental Study, Engine Calibration

\section{INTRODUCTION}

In spite of the increasing torque and performance requirements of diesel engines, the reduction in emission limits and the improvement in fuel consumption put a great deal of burden on engine manufacturers. The torque, performance and fuel consumption, which are directly proportional to the efficiency of combustion, increase the thermal and mechanical loads in the cylinder. During the operation of the engine a pressure rise occurs due to the internal combustion process. During this pressure rise, the maximum pressure is called the maximum internal pressure within the cylinder. One of the conditions required for the engine to continue to operate in a healthy way is that no pressure value during combustion exceeds the maximum pressure resistance limit of the cylinder. The maximum pressure in the cylinder reaches up to 200 bar (even higher on heavy commercial vehicles). The higher the maximum compressive strength of the engine in the cylinder, the more efficient combustion will be achieved and the amount of torque taken from the engine will increase [1]. During the engine development tests, the maximum pressure inside the cylinder must be monitored. When these values exceed the resistance, actions must be taken to protect the engine. Today, maximum pressure values are followed by engine cylinder pressure sensors.

These sensors are usually installed by means of an adapter instead of the glow plug. When both sensors and glow plugs are needed, the engine head must be machined. This process will affect the internal turbulence of the cylinder.

On the other hand, there are disadvantages such as drifting as a result of the use of sensors, high costs due to high pressure, installation of one cylinder per cylinder, use of amplifier, module and computer [2]. In this context the peak firing pressure (PFP) data is monitored via developed computer algorithms to prevent from damage that arouses from sensor faults and etc.

In the automotive sector, there lots of modelling techniques that are used. Some of them are using massive and complex algorithms. But these modelling techniques are generally needs more computing time for calculation. Considering to the diesel engines maximum rotation speed (i.e. $6000 \mathrm{rpm}$ ) there is 3000 PFP peaks are created and all of these peaks should be monitored in a predefined accuracy.

The ANN approach is a new, fast calculation methodology that does not require complex mathematical equations to explain a non-linear and multidimensional system. Over the last decade, more attention has been paid to ANN techniques, particularly in the 
automotive industry, which has widely accepted ANN as technology offering an alternative solution for engineering problems [3, $4,5]$. Artificial neuron" is used in the ANN terminology to show the similarities between the developed mathematical system and the human brain including the transfer of signals through synapses in the human body $[5,6,7]$.

The ANN are capable of predicting the consequences of future situations by feeding on the available data. As some scientific studies have shown, ANN is a very popular modeling technique for estimating pressure and emission values [8,9]. The working principle of ANN is given in Figure 1.1 [9]. Also a detailed mathematical model of ANN can be found in Haykin's Book [7].

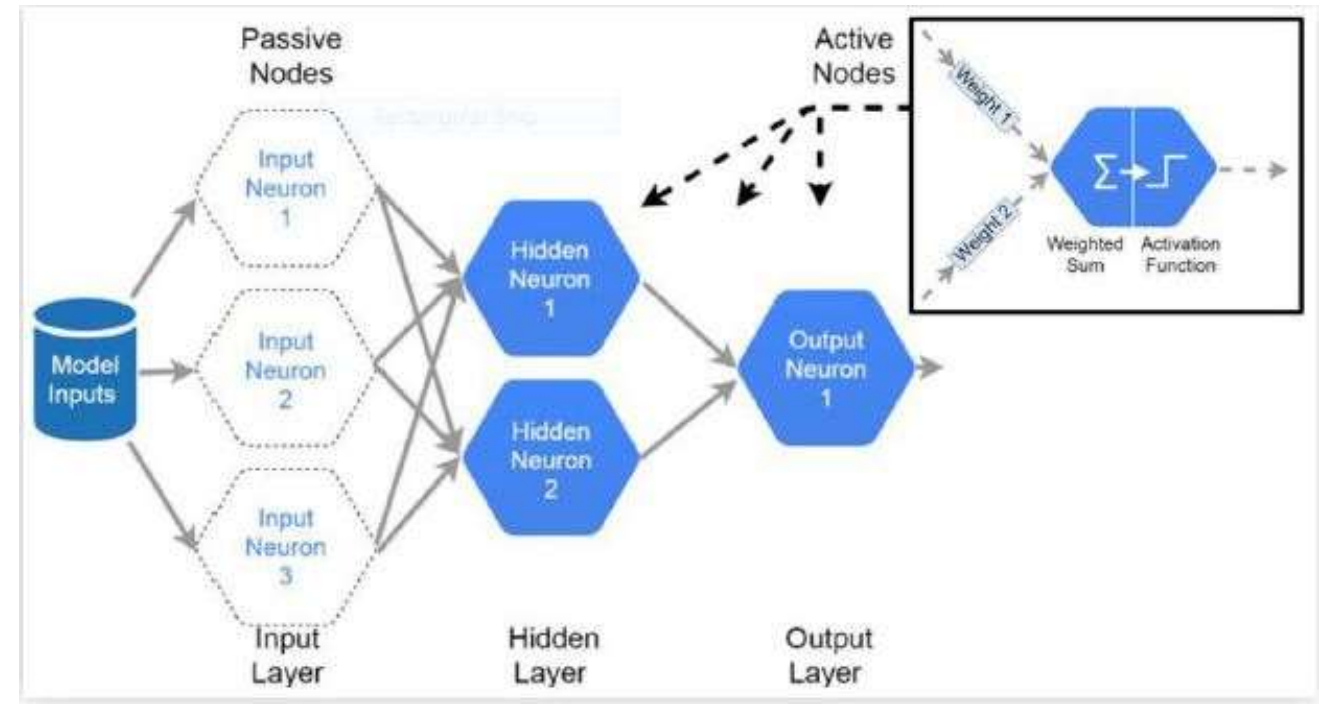

Figure 1.1: Feedforward neural network with 3 inputs and 2 hidden neurons [9]

There are valuable research works in the literature about usage of ANN in internal combustion engines. Uzun [10] used the ANN method to perform parametric studies on diesel engines .They used engine speed, injection advance (IA), and engine load variation as input to ANN. The brake specific fuel consumption as out for ANN. They used multilayer preceptors (MLP) type ANN. The correlations obtained with the real output and the simulated output of the ANN were found to be reliable Yuanwang et. al. [11] presented ANN model that predicts the exhaust emissions from an engine. They used the total cetane number, base cetane number and cetane improver, total cetane number and total nitrogen content in the diesel fuel as neural network inputs. The ANN accuracy was found in an acceptable range. He and Rutland [3] used engine speed, engine load, start of injection, injection pressure, mass of the first injection pulse of a split injection, boost pressure and exhaust gas re-circulation. The output parameters of the ANN is cylinder pressure, cylinder temperature, cylinder wall heat transfer, NOX emission, and soot emission are the outputs of ANN. They also studied the effect of prior knowledge on ANN methodology. . They discovered that with prior knowledge, the general performance of the ANN was improved compared to the networks that were designed without prior knowledge. Also Canakci et al. [12], Parlak et. al. [13], Ganapathy [14], Oguz et. al. [15], Lucas et al. [16] ANN for predicting engine performance parameters.

\section{MATERIAL AND METHODS}

\subsection{Experimental Setup}

The engine properties used in the experiment is given in Table 2.1. This engine was loaded with AVL Dyno Exact APA 204/8 dynamometer and the values were obtained by using AVL PUMA test automation system.

Table 2.1: Characteristics of engine

\begin{tabular}{|l|l|}
\hline Engine type & Diesel \\
\hline Emission type & Euro6 \\
\hline Displacement $(\mathrm{L})$ & 2.0 \\
\hline Number of cylinders & 4 \\
\hline Stroke $(\mathrm{mm})$ & 86 \\
\hline Rod(mm) & 160 \\
\hline Diameter of piston $(\mathrm{mm})$ & 86 \\
\hline Compression ratio & 16 \\
\hline
\end{tabular}


The ATI Vision [17] program is used for all values read from the ECU. Fuel injection values were read from the ECU and verified by the measurements of the AVL 735 fuel device. The rail pressure is read directly from the sensor connected to the ECU. The boost temperature and boost pressure information are obtained by means of the instruments in the intake manifold. The amount of air was read directly from the sensor connected to the ECU and verified by the AVL SENSYFLOW. The engine speed was read directly with the sensor connected to the ECU and the dynamometer was verified with its own speed sensor. Target cylinder incylinder pressure data used to train the model the readings of the AVL GU22C type pressure sensor are enhanced by the AVL Indismart amplifier and expressed in the AVL INDICOM software with the crank angle sensor information. The engines DOE was removed for use in engine development tests and more than 2400 points were obtained. The models with these measurement points were tested with new 66 unused measurement points that is not used during training phase. After the values of the engine were fixed, it was recorded for 30 seconds and the measurement point was obtained as the mean value.

Test system configuration is given in Figure 2.1 [18].

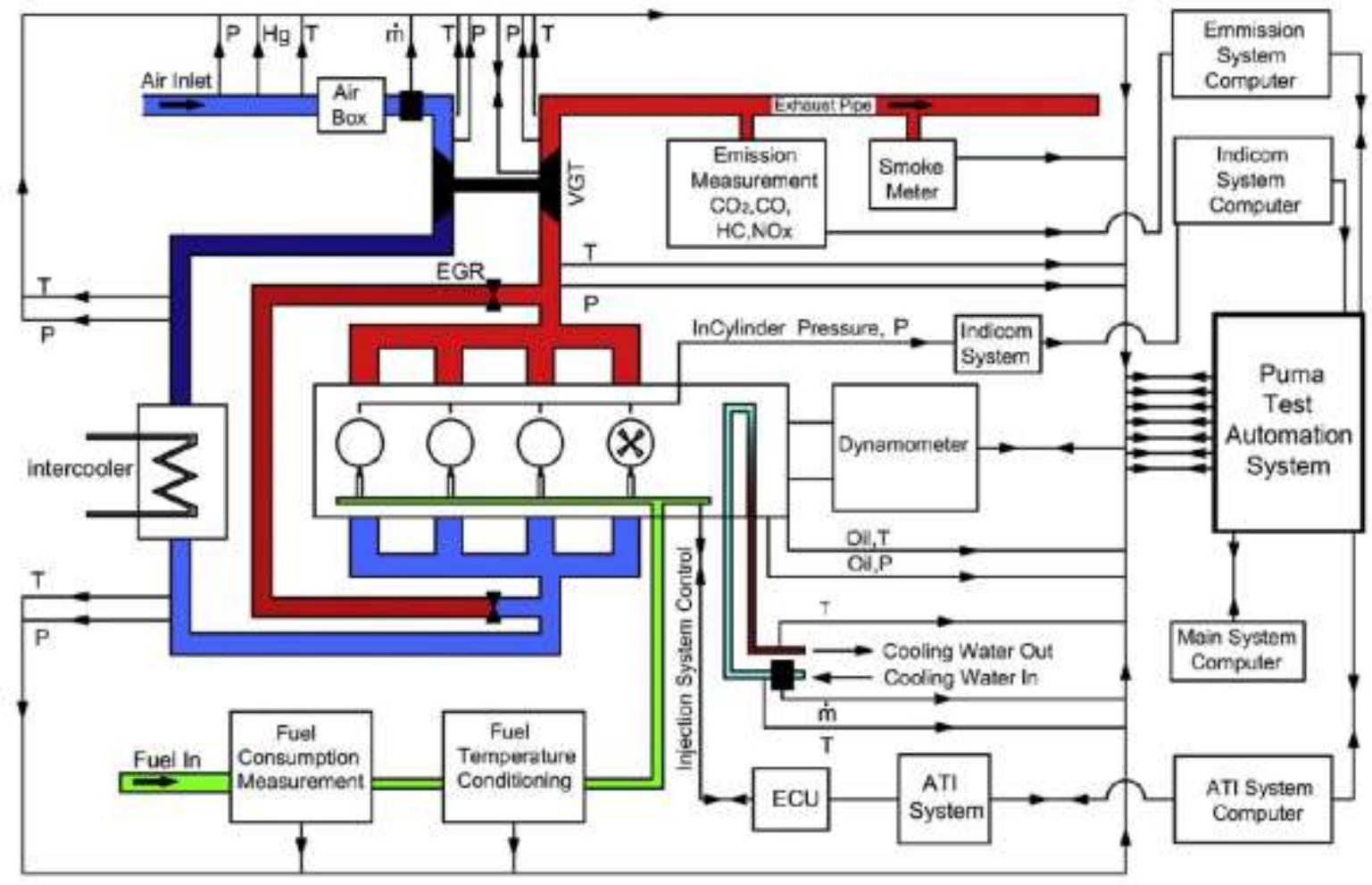

\subsection{ANN Model Design}

Figure 2.1: Test Cell Layout [18]

The number of neurons, training algorithms, inputs and outputs to be used when performing the ANN model should be well established. In this study, inputs, outputs and training algorithm for the model to be produced with MATLAB nntool [19] toolbox are predetermined. Also, the optimum number of neurons will be determined during this research. The used inputs and their varying ranges are given at Table 2.2 and parameters are selected according to [20, 21].

Table 2.2: DOE Points Range

\begin{tabular}{|l|l|l|}
\hline Parameter & Min & Max \\
\hline Pilot Injection Angle & $70\left({ }^{\circ} \mathrm{BTDC} *\right)$ & $7\left({ }^{\circ} \mathrm{ATDC} *\right)$ \\
\hline Pilot Injection Amount & $0(\mathrm{mg} / \mathrm{hub})$ & $3(\mathrm{mg} / \mathrm{hub})$ \\
\hline Main Injection Angle & $\left.25\left({ }^{\circ} \mathrm{BTDC}\right)^{*}\right)$ & $9\left({ }^{\circ} \mathrm{ATDC} * *\right)$ \\
\hline Main Injection Amount & $0(\mathrm{mg} / \mathrm{hub})$ & $68(\mathrm{mg} / \mathrm{hub})$ \\
\hline Engine speed & $800(\mathrm{rpm})$ & $4800(\mathrm{rpm})$ \\
\hline Ray pressure & $7\left(\mathrm{MPa}^{* * *}\right)$ & $180\left(\mathrm{MPa}^{* * *}\right)$ \\
\hline Boost Temperature & $20\left({ }^{\circ} \mathrm{C}\right)$ & $146\left({ }^{\circ} \mathrm{C}\right)$ \\
\hline Boost Pressure & $0(\mathrm{mbar} * * *)$ & $1610(\mathrm{mbar} * * *)$ \\
\hline Air Quantity & $0(\mathrm{mg} / \mathrm{hub})$ & $1270(\mathrm{mg} / \mathrm{hub})$ \\
\hline $\begin{array}{l}\text { * BTDC: Before Top Dead Centre } \\
\text { ** ATDC: After Top Dead Centre } \\
* * * \text { All pressure values are absolute }\end{array}$ & & \\
\hline
\end{tabular}


In this context a 2400 point DOE data is created with varying of these parameters.

The Bayesian algorithm was chosen as the training algorithm. The reason why this training algorithm is chosen is that the engine data is noisy [22]. The trained models, then tested in the same type of engine development testing conducted and the results were analyzed.

\section{RESULTS AND DISCUSSION}

Model training was started using MATLAB nntool application with using the test results of DOE data explained at Section 2.2 from experimental engine.

In order to determine the optimum number of neurons, MATLAB nntool has been trained with the number of neurons from the default of 1 neurons to 20 neurons. The used neurons numbers during this phase are 1, 2, 3, 5, 10 and 20. The regression graphics of all ANN's with different neuron numbers are given in Table 3.1.

Table 3.1: ANN models' $R$ and MSE values

\begin{tabular}{|c|c|c|c|c|c|}
\hline \multirow{2}{*}{ ANN Models } & \multicolumn{2}{|c|}{ Training } & \multicolumn{2}{c|}{ Testing } & All \\
\cline { 2 - 6 } & R & MSE & R & MSE & R \\
\hline 1 Neuron Model & 0.94859 & $79.80 \mathrm{E}-0$ & 0.94809 & $69.86 \mathrm{E}-0$ & 0.94858 \\
\hline 2 Neurons Model & 0.98308 & $27.16 \mathrm{E}-0$ & 0.97992 & $20.12 \mathrm{E}-0$ & 0.98293 \\
\hline 3 Neurons Model & 0.9878 & $17.30 \mathrm{E}-0$ & 0.99056 & $39.89 \mathrm{E}-0$ & 0.98795 \\
\hline 5 Neurons Model & 0.99151 & $13.86 \mathrm{E}-0$ & 0.98333 & $14.02 \mathrm{E}-0$ & 0.99116 \\
\hline 10 Neurons Model & 0.99459 & $9.11 \mathrm{E}-0$ & 0.97943 & $10.15 \mathrm{E}-0$ & 0.99381 \\
\hline 20 Neurons Model & 0.9962 & $5.98 \mathrm{E}-0$ & 0.97297 & $24.83 \mathrm{E}-0$ & 0.99529 \\
\hline
\end{tabular}

Then these created 6 ANN model is tested again with unused 66 test points that is not used at the training and validation phase of them. The peak firing pressure (PFP) difference of this five ANN is given at Figure 3.1. 20 neurons model have not shown in figure because too much difference with sensor output.

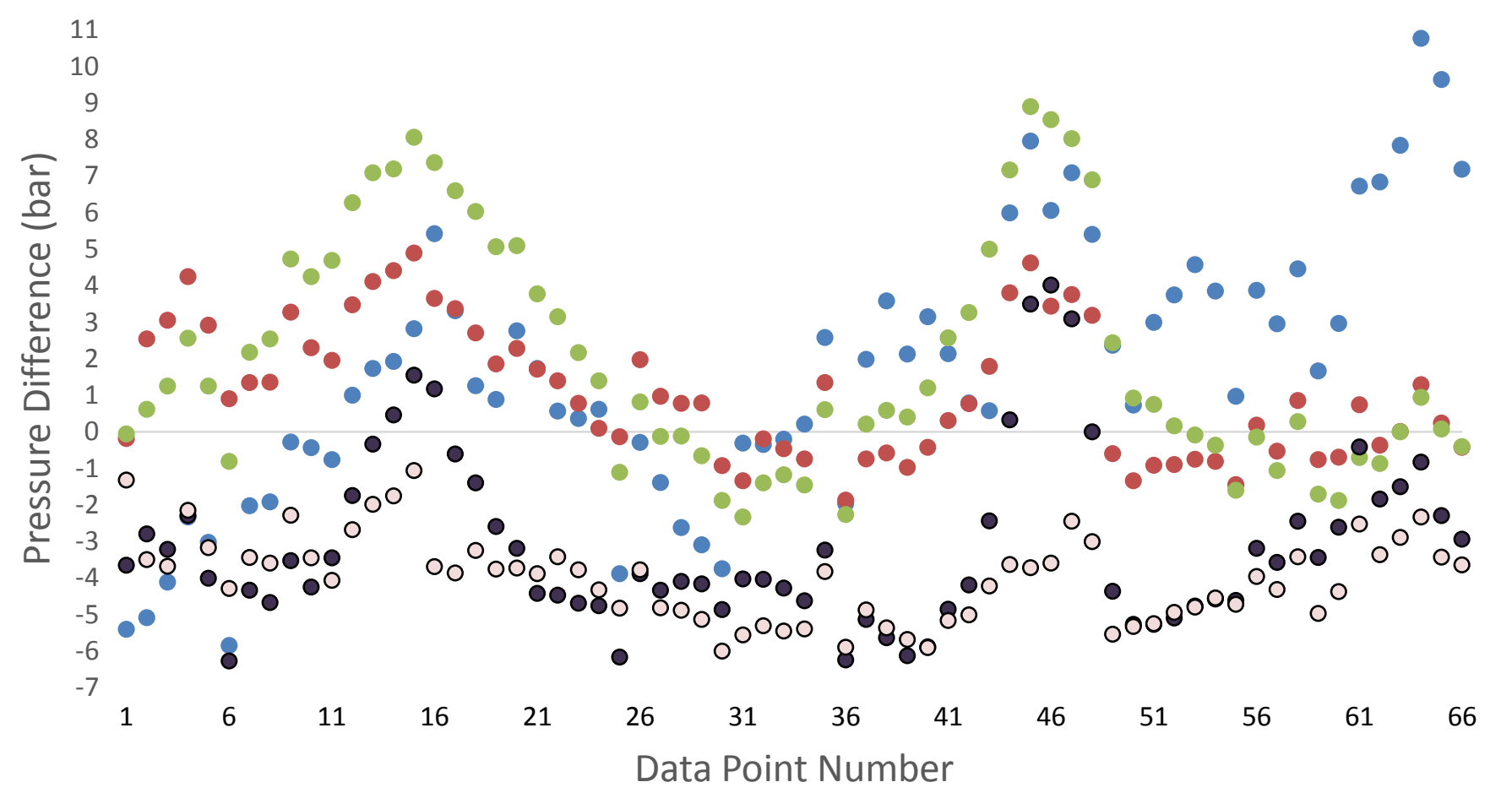
- 1 Neurons
- 2 Neurons
- 3 Neurons
5 Neurons
o 10 Neurons

Figure 3.1: ANN models comparison with sensor measurement 
It was decided that the best result from the six models obtained after the above studies was the model with 2 neurons. Results given in Table 3.2.

Table 3.2: Results of ANN Models

\begin{tabular}{|l|l|l|l|}
\hline Models & Maximum Diff [bar] & Minimum Diff [bar] & Average Diff [bar] \\
\hline 1 Neuron Model & 10.7557 & 0.2063 & 3.1371 \\
\hline 2 Neurons Model & 4.8865 & 0.0028 & 1.6278 \\
\hline 3 Neurons Model & 8.8915 & 0.0065 & 2.6535 \\
\hline 5 Neurons Model & 6.2721 & 0.0081 & 3.5192 \\
\hline 10 Neurons Model & 6.0093 & 1.0683 & 4.0042 \\
\hline 20 Neurons Model & 52.2615 & 7.3695 & 29.1248 \\
\hline
\end{tabular}

On the other hand, this study shows that as the number of neurons in the model increased, the model gave better results only in the trained conditions, while the model with the optimal neuron number reached at the end of the study yielded better results in untrained working conditions.

\section{CONCLUSION}

In this study a novel approach that is used in today's technology the ANN was used to predict in PFP of a diesel engine. The PFP was modeled with 9 inputs (pilot injection angle, pilot injection amount, main injection angle, main injection amount, engine speed, ray pressure, boost pressure, boost temperature, air quantity) via using Bayesian algorithm. The 2400 engine test point was used for creating 6 different ANN which different number of neurons. The number of 1, 2, 3, 5, 10 and 20 neurons are used for creating ANNs. The trained and validated ANN regressions are in 0.98-0.99 Range. Then these ANN are tested again with 60 unused new test points and results are evaluated. The results showed that 2 neuron ANNs are the best predicting ANN systems for the tested engine. Also it was showed that ANN can be used to predict the engine parameters fast with a good accuracy.

\section{REFERENCES}

[1] T. Hamm, M. Rebbert, H. J. Ecker, M. Graffen, Cylinder Head Design for High Peak Firing Pressures, SAE Paper No: 2008-01-1196, 2008.

[2] Y. Ura and K. Oya, Pressure Sensor Module for High Temperature, High Pressure, and Quick Response, SAE Paper No: 2018-01-0759, 2018.

[3] He, Y., Rutland, C. J., Application of Artificial Neural Networks in Engine Modeling, International Journal of Engine Research, 5 (2004), 4, pp. 281-296

[4] Zhou, H., et al., Modeling and Optimization of the NOx Emission Characteristics of a Tangentially Fired Boiler with Artificial Neural Networks, Energy, 29 (2004), 1, pp. 167-183

[5] O. Ozener, L. Yuksek, M. Ozkan, Artificial Neural Network Approach to Predicting Engine-Out Emissions and Performance Parameters of a Turbo Charged Diesel Engine, Thermal Science, (2013), vol. 17 no. 1 pp. 153-166

[6] Karonis, D., et al., A Neural Network Approach for the Correlation of Exhaust Emissions from a Diesel Engine with Diesel Fuel Properties, Energy \& Fuels, 17 (2003), 5, pp. 1259-1265

[7] Haykin, S., Neural Networks: A Comprehensive Foundation, Prentice Hall, New York, USA, 1998

[8] A. M. Bertram and S.C. Kong, Augmentation of an Artificial Neural Network (ANN) Model with Expert Knowledge of Critical Combustion Features for Optimizing a Compression Ignition Engine Using Multiple Injections, SAE Paper No: 2017-01-0701, 2017.

[9] A. D. Sediako, J. Andric, J. Sjoblom, E. Faghani, Heavy Duty Diesel Engine Modeling with Layered Artificial Neural Network Structures, SAE Paper No:2018-01-0870,2018.

[10] Uzun, A., A Parametric Study for Specific Fuel Consumption of an Intercooled Diesel Engine Using a Neural Network, Fuel, 93 (2012), March, pp. 189-199

[11] Yuanwang, D., et al., An Analysis for Effect of Cetane Number on Exhaust Emissions from Engine with the Neural Network, Fuel, 81 (2002), 15, pp. 1963-1970

[12] Canakci, M., et al., Prediction of Performance and Exhaust Emissions of a Diesel Engine Fueled with Biodiesel Produced from Waste Frying Palm Oil, Expert Systems with Applications, 36 (2009), 5, pp.9268-9280

[13] Parlak, A., et al., Application of Artificial Neural Network to Predict Specific Fuel Consumption and Exhaust Temperature for a Diesel Engine, Applied Thermal Engineering, 26 (2006), 8-9, pp. 824-828

[14] Ganapathy T., et al., Artificial Neural Network Modeling of Jatropha Oil Fueled Diesel Engine for Emission Predictions, Thermal Science, 13 (2009), 1, pp. 91-102

[15] Oguz, H., et al., Prediction of Diesel Engine Performance Using Biofuels with Artificial Neural Network, Expert Systems with Applications, 37 (2010), 9, pp. 6579-6586 
[16] de Lucas, A., et al., Modeling Diesel Particulate Emissions with Neural Networks, Fuel, 80 (2001), 4, pp. 539-548

[17]***, ATI Vision, https://www.accuratetechnologies.com/ECUCalibration/VISIONSoftware, 2019

[18] M. Özkan, D. B. Özkan, O. Özener, H. Y1lmaz, Experimental study on energy and exergy analyses of a diesel engine performed with multiple injection strategies: Effect of pre-injection timing, Applied Thermal Engineering 53 (2013) $21 \mathrm{e} 30$

[19] ***, MATLAB, https://www.mathworks.com/help/deeplearning/getting-started-with-deep-learning-toolbox.html , 2019

[20] O. Grondin, C. Letellier, J. Maquet, L. A. Aguirre, F. Dionnet, Direct Injection Diesel Engine Cylinder Pressure Modelling via NARMA Identification Technique, SAE Paper No: 2005-01-0029, 2005.

[21] B. S. Jander and R. Baar, Modeling Thermal Engine Behavior Using Artificial Neural Network, SAE Paper No: 2017-010534, 2017.

$[22] * * *$, MATLAB,

https://www.mathworks.com/help/deeplearning/ref/trainbr.html;jsessionid=dc2af2276beed333128057bd1978, 2019 